\title{
Obesity in kidney transplant donors and recipients: does the benefit outweigh the risk?
}

\author{
Smaragdi Marinaki ${ }^{1 *}$, Pelagia Kriki ${ }^{2}$, Kyriaki Kolovou ${ }^{1}$ and John N. Boletis ${ }^{1}$ \\ ${ }^{1}$ Department of Nephrology and Transplantation Unit, National and Kapodistrian University of Athens, Medical School, General Hospital Laiko, Greece \\ ${ }^{2}$ Department of Nephrology, Democritus University of Thrace, University Hospital, Greece
}

\begin{abstract}
Overweight and obesity has reached epidemic proportion worldwide and has been described as a global pandemic. Obesity is recognized as a major and independent risk factor for cardiovascular death and its prevalence has risen dramatically over the past two decades. Similar to the general population, patients with chronic kidney disease are also increasingly obese. Contrarely, in patients with ESRD the reverse epidemiology of the obesity paradox seems to protect the hemodialysis population from cardiovascular death. Among kidney transplant recipients, overweight and obesity prevalence has risen with $60 \%$ of kidney transplant candidates being overweight or obese at the time of transplantation. Though recipient obesity negatively impacts the access to transplantation, after transplantation, short and long term outcomes are very good. The surgical procedure is not associated with major complications or death. Short term outcomes are excellent except an increased incidence of delayed graft function while long term there is a definite survival advantage compared to HD. Furthermore, prevalence of overweight and obesity rises in living kidney donors similar to the general population. Obesity related glomerulopathy, a variant of focal and segmental glomerulosclerosis, is the clinicopahtologic entity that best describes the process of kidney damage in obese individuals. Since thepathophysiologic process is similar to that of secondary FSGS due to reduced nephron mass, it may be accelerated after kidney donation. In the absence of definite guidelines, overweight donors must be informed about the increased risk of donation and obese $\left(\mathrm{BMI}>30 \mathrm{Kg} / \mathrm{m}^{2}\right)$ donors have to be excluded from donation, at least until they lose weight. Undoubtedly the transplantation community faces a new, emerging problem: the definite advantage of survival following renal transplantation and the dramatically increased prevalence of overweight and obesity between transplant recipients and donors.
\end{abstract}

\section{Introduction}

Assessment of nutritional status in patients and in the general population is important, as malnutrition and obesity have both been associated with decreased survival. Body mass index (BMI) is a more reliable indicator of nutritional status than the simple measurement of body weight. It is a useful marker, easy to calculate and it is defined as the weight in kilograms divided by the square of the height in meters $\left(\mathrm{kg} / \mathrm{m}^{2}\right)$. It may overestimate weight in muscular individuals and underestimate it in elderly persons or patients with cachexia and reduced muscle mass [1].

Ideal BMI has been established on the basis of cardiovascular mortality through long-term monitoring in large population studies [2]. Increased body mass index is an independent risk factor for mortality due to ischemic heart disease, stroke, colon, endometrial and postmenopausal breast cancer.

A review of 57 prospective studies in a total of 900,000 people showed that people of both sexes had the lowest mortality at a BMI between $22.5-25 \mathrm{Kg} / \mathrm{m}^{2}$. Above this limit, any increase of BMI by $5 \mathrm{Kg} / \mathrm{m}^{2}$ resulted in an increase in all-cause mortality for all age and sex groups by $30 \%$. Especially cardiovascular mortality rose by $40 \%$, mortality due to cancer by $10 \%$ and mortality due to respiratory and other causes by $20 \%$. BMI between $30-35 \mathrm{Kg} / \mathrm{m}^{2}$ resulted in a median survival reduction by $2-4$ years while BMI between $40-45 \mathrm{Kg} / \mathrm{m}^{2}$ reduced median survival by $8-10$ years [2]. It should be noted that in patients with a low $\mathrm{BMI}<22.5 \mathrm{Kg} / \mathrm{m}^{2}$, particularly those with values $<20 \mathrm{Kg} / \mathrm{m}^{2}$, mortality also increased mainly due to respiratory diseases and specific types of smoking associated cancer [2].
On the basis of cardiovascular mortality data, the National Health Institute (NIH) and the World Health Organization (WHO) developed a classification system of obesity according to BMI. In Caucasians, Hispanics and African Americans it defines as underweight people with $\mathrm{BMI}<18.5 \mathrm{Kg} / \mathrm{m}^{2}$, normal weight those with a BMI between 18.5 to 24.9 $\mathrm{Kg} / \mathrm{m}^{2}$ and overweight individuals with BMI $>25-29.9 \mathrm{Kg} / \mathrm{m}^{2}$. Obesity is defined as a BMI $>30 \mathrm{Kg} / \mathrm{m}^{2}$ and is further classified as follows: Class I obesity: BMI 30-34.9 Kg/m², Class II severe obesity: BMI 35-39.9 Kg/ $\mathrm{m}^{2}$, Class III or morbid obesity: BMI $\geq 40 \mathrm{Kg} / \mathrm{m}^{2}$. This definition differs for the Asian population, as the negative impact of BMI on overall and cardiovascular mortality is observed at lower BMI levels in this population. Asians are classified as overweight at a BMI between 23 and $24.9 \mathrm{Kg} / \mathrm{m}^{2}$ and obese at a BMI over $25 \mathrm{Kg} / \mathrm{m}^{2}$ [2].

Waist circumference (WC) is an additional marker that has been associated with cardiovascular mortality. Men with a waist circumference $>102 \mathrm{~cm}$ and women with a waist circumference $>88 \mathrm{~cm}$ have an increased cardiovascular risk. Patients with central or visceral obesity are at increased risk for developing diabetes mellitus, coronary

Correspondence to: Smaragdi Marinaki, Department of Nephrology and Transplantation Unit, National and Kapodistrian University of Athens, Medical School, General Hospital Laiko, Agiou Thoma 17, Goudi, Athens, 11527, Greece, Tel: +0030-210-7456351, Fax: 0030-213-2061243; E-mail: laikneph@laiko.gr

Key words: body mass index, kidney recipient survival, kidney transplant survival, obese kidney donor, obese kidney transplant recipient, obesity, obesity related glomerulopathy

Received: April 09, 2016; Accepted: May 05, 2016; Published: May 09, 2016 
heart disease, hypertension, dyslipidemia and fatty liver [2].

The rising prevalence of overweight and obesity in several countries has been described as a "global pandemic". During 1980-2013 the increase in the incidence of obesity in the general population was dramatic. The proportion of adults with a body mass index (BMI) of $25 \mathrm{Kg} / \mathrm{m}^{2}$ or greater, increased between 1980 and 2013 from $28.8 \%$ to $36.9 \%$ in men, and from $29.8 \%$ to $38.0 \%$ in women [3].

The World Health Organization has already raised alarm on the adverse impact of the increasing rates of obesity on the population's health and forces all countries to systematically record and to more effectively intervene in order to at least inhibit the rate of growth by 2025.

This increase in obesity is observed in both developing and developed countries but with different sex patterns. In developed countries, the overall incidence of overweight and obesity (BMI> 25 $\mathrm{Kg} / \mathrm{m}^{2}$ ) is higher in men than in women though in developing countries more women than men are overweight and obese. The incidence of obesity $\left(\mathrm{BMI}>30 \mathrm{Kg} / \mathrm{m}^{2}\right)$ is also increasing in both developed and developing countries and is higher in women than in men. Rates were increasing between 1992-2002 but the rate of increase has slowed down after 2002 [3].

Coming to the prevalence of obesity in patients with Chronic Kidney Disease, though they represent a special patient group with increased cardiovascular risk, there are no available data, only those which are extrapolated from the general population. On contrary, there are several studies in patients with end stage renal disease (ESRD). In a report from the US Renal Data System (USRDS) from 2000, Kasiske et al. [4] analysed the impact of BMI in hemodialysis patients. Among 30.614 patients initiating renal replacement therapy, the mean BMI was $26.0 \mathrm{Kg} / \mathrm{m}^{2}$. A lower incidence of obesity was observed in hemodialysis patients compared to the general population.

Since 2000, there is an increasing trend towards higher BMI levels in those patients too.

In a more recent study, Friedman et al. [5] analyzed data from 85,000 prospective kidney transplant recipients and reported an increase in the incidence of obesity in this patient group too. The majority $(60 \%)$ of patients were overweight or obese at the time of transplantation. Between 1987 and 2001, the proportion of obese transplant recipients rose by $116 \%$, in parallel to the general population. The highest prevalence of obesity was observed among those aged 5070 years, those with diabetes mellitus type II and in women.

It is also worth mentioning the obesity paradox observed in hemodialysis patients. This is the phenomenon of "reverse epidemiology" of obesity in the population of patients with ESRD on hemodialysis. In contrary to the general population, in patients on hemodialysis, higher BMI not only is not associated with increased mortality, on contrary, in this patient population, mortality is reduced at higher levels of BMI.

This finding is consistent and has been reported in many ESRD cohorts. It is observed at all levels of high BMI, even in severe obesity and is independent of factors associated with recent advances in HD techniques such as better biocompatibility of dialysis membranes or developments in medication. It is also independent of regional and racial differences or co morbidities [6-11].

Johansen et al. [12] analyzed USRDS data of 415.000 patients on dialysis between 1995 and 2000. Increased BMI was associated with reduced all-cause mortality, even at very high BMI levels $\left(>37 \mathrm{Kg} / \mathrm{m}^{2}\right)$ for all races except Asians. These data did not change even when other nutrition assessment markers were used such as lean body mass index (LBMI) or Benn index [12].

There are plausible explanations for this apparently "paradox". It is well established that hemodialysis represents a state of chronic inflammation and hypercatabolism (protein energy waisting (PEW). Chronic inflammation and malnutrition are both independent risk factors for cardiovascular mortality. Cosequently, increased body mass at least at dialysis initiation seems to act protectivelly [6].

An increase in the percentage of overweight and obese kidney transplant candidates was recorded in the study of Segev et al., published in 2008 [13]. In a prospective cohort of 132,353 patients who were registered for kidney transplantation in the United States between 1995 and 2006 they analysed the different categories according to BMI. From the entire cohort, a $34.3 \%$ of patients were overweight, $19.3 \%$ obese while $7.2 \%$ were classified as severely obese (class II- BMI 35-40 $\mathrm{Kg} / \mathrm{m}^{2}$ ) and $2.7 \%$ as morbidly obese (Class III BMI $>40 \mathrm{Kg} / \mathrm{m}^{2}$ ). The interesting point in this study is that the increasing degree of obesity was associated with a reduction in the likelihood of receiving a transplant: $2.7 \%$ for obese candidates, which rose to 24 to $28 \%$ in those with severe obesity and $42-44 \%$ in candidates with morbid obesity. The authors of this article point out that although the final decision to proceed to transplantation for every given donor and recipient depends on clinical judgment, there may be a restricting policy concerning obese kidney transplant candidates. That means that high BMI is commonly used as a preface to exclude otherwise healthy individuals from transplantation.

Given the continuous increase in the prevalence of obesity in the general population as well as in hemodialysis patients and given the clear survival advantage of transplantation over hemodialysis, the transplantation community faces a new, ongoing problem: growing numbers of obese transplant candidates at the waiting lists, often without other co- morbidities.

Few data exist-if any- to suggest if there is a BMI level above which patients should be denied transplantation. The guidelines for managing obesity in this special patient group are also sparse.

The American society of Transplantation recommends supervised weight loss for obese candidates with target $\mathrm{BMI}<30 \mathrm{Kg} / \mathrm{m}^{2}$ with lifestyle modification and with close medical monitoring of the nutritional status. It is also stated that no patient should be excluded from transplantation according to obesity per se [4]. Canadian guidelines (Canadian Society of Transplantation) are practically identical [14].

To assess the true benefit of transplantation in obese individuals, one has to answer the following questions:

1. How reliable is the BMI as an index of obesity in the hemodialysis and transplanted population?

2. What is the impact of high recipient BMI on early posttranplant period?

3. What is the impact of high recipient BMI on long-term allograft and patient survival?

\section{Limitations of BMI}

BMI has limitations as a nutritional assessment marker. The most important is that it does not quantify the proportion of muscle and adipose tissue. Chan et al. [15] describes the mechanism through which the combination of reduced muscle mass and increased adipose 
tissue-the phenomenon of "sarcopenic obesity", which can be observed in "normal weight" individuals according to BMI, negatively impacts patient survival. Reduced muscle mass is associated with worsening of musculoskeletal, respiratory and cardiac function with negative impact on tissue oxygenation. It consequently promotes oxidative stress and inflammatory activity. On the other hand, increased adipose tissue, mainly abdominal obesity, is associated with chronic inflammation. Adipose tissue is a metabolically active system that releases inflammatory cytokines, the so-called adipokines such as interleukin IL-6, Tumor Necrosis Factor TNF- $\alpha$, leptin and resistin. These cytokines activate prothrombin and other adhesion molecules resulting in vascular endothelial dysfunction,inflammation and accelerated atherosclerosis $[15,16]$.

\section{Impact of high recipient BMI on early posttransplant period}

The main problems concerning of overweight and obese recipients during the early posttransplant period are: a) surgical complications and longer hospital stay and b) the rate of delayed graft function and acute rejection.

\section{Surgical complications/duration of hospital stay}

In a retrospective analysis of 448 kidney transplantations Furriel et al. [17] compared outcomes during the early posttranplantation period between normal weight, overweight, and obesity groups. Overweight were $28.3 \%$ of the kidney transplant recipients and obese $5.8 \%$. Both overweight and obese groups had longer surgery duration compared to the normal weight group (median surgery duration $>3 \mathrm{~h}$ in $22.8 \%$ and $42.3 \%$ of patients respectively versus $20.7 \%$ in the normal weight group). Surgical complication rates were higher in both non-normal weight groups $(17.3 \%$ and $26.9 \%$ vs. $15,9 \%$ in the normal weight group), especially lymphocele formation $(P=0.031)$ and wound dehiscence $(P<0,005)$. However, no difference was detected concerning the postoperative length of stay and patient and graft survival between the three groups. No major surgical complications, graft loss or deaths occured in either group [17].

Cacciola et al. [18] analyzed the outcomes of obese kidney transplant recipients .In this study, a total of one hundred and fourteen renal transplantations were performed between 1993 and 2003. Patients were divided into two groups: Group A with moderate obesity (BMI $30-35 \mathrm{Kg} / \mathrm{m}^{2}$ ) and Group B with morbid obesity (BMI $>35 \mathrm{Kg} /$ $\mathrm{m}^{2}$ ). Wound infection rates were similar between the 2 groups $(22 \%$ in group A vs. 25\% in group B). Patient and graft survival at 1 year was worse in the morbid obesity group (patient survival $87.5 \%$ vs. $98.9 \%$ $[\mathrm{p}=0.007]$ and graft survival $75 \%$ vs. $93.9 \%[\mathrm{p}<0.001]$ respectively. The authors conclude that overall outcomes of obese recipients were inferior compared to normal weight recipients, as expected [18]. However, obese patients should be categorized based on BMI, in order to distinguish those with mild to moderate from those with morbid obesity since patients with mild and moderate obesity have excellent outcomes.

\section{Impact of increased BMI on delayed graft function and acute rejection}

Cannon et al. [19] performed a retrospective review of all renal transplant recipients in the United Network for Organ Sharing database from 2004 through 2010. They assessed the impact of delayed graft function (DGF) and graft survival in different weight classes of obese recipients. In a total of 74.983 kidney recipients $20 \%$ were classified as class I obesity $(\mathrm{n}=15.010), 7.7 \%$ as class II $(\mathrm{n}=5744)$ while $2.1 \%$ as class III $(\mathrm{n}=1561)$.

Multivariate logistic regression analysis showed a significantly increased risk for DGF with increasing rates of obesity (OR 1.34 1.68 and $2.68 \mathrm{CI}: 95 \%)$ while patients in class II and III obesity were at increased risk for graft failure compared to their non-obese counterparts [19].

In a retrospective single-center study, Weissenbacher et al. [20] analyzed data from 1132 kidney recipients and they revealed an increased rate of DGF even in overweight patients (40,9\% vs. $29,8 \%$ in normal weight recipients, $\mathrm{p}=0.0001$ ) while in obese patients, DGF rate rose to $52,5 \%(\mathrm{p}=0.0001)$. In this study the authors also analysed the incidence of biopsy proven acute rejection (BPAR) in this patient population. The overall incidence of BPAR was $14.6 \%$ (24.9\% in the group with DGF vs. $9.7 \%$ in the non-DGF group [ $\mathrm{p}=0.0001]$ ). Given the higher incidence of DGF in obese recipients, there seems to be an indirect correlation between obesity and acute rejection episodes during the early posttransplantation period [20].

\section{Impact of BMI on long term renal transplant outcomes}

In the largest cohort so far, Meier-Kriesche et al. retrospectively analysed data of the USRDS among 51.927 kidney transplant recipients. This study revealed a strong and independent association of BMI with patient and graft survival with the form of a J curve [21]. The extremes of both very high and very low recipient BMI at renal transplantation were associated with significantly worse patient and graft survival. The true survival benefit in obese transplant recipients can only be assessed, when comparing them to those remaining on hemodialysis. This is very clearly shown in a study by Glanton et al. [22] in 7521 patients again from the USRDS database. This study revealed a $61 \%$ reduction in mortality risk in transplant patients compared to patients remaining on HD, even in the group of obese patients. In the cohort of obese patients the authors a decrease in death rate from 6.6 to 3.3/100patient/ year was recorded after kidney transplantation comparable to that $(2,8 / 100$ patients/year) in the normal weight group. The authors conclude that obese ESRD patients have a clear survival advantage after transplantation compared to those remaining on hemodialysis [22].

A meta-analysis published in 2015 confirmed the very good results both in short and long-term outcomes of obese kidney transplant recipients. Seventeen studies including a total of 138.081 obese recipients $\left(\mathrm{BMI}>30 \mathrm{Kg} / \mathrm{m}^{2}\right)$ were included. Despite the higher likelihood of DGF (OR:1.68,95\% CI:1.39-2.03), obese transplant recipients have only a slightly increased risk of graft loss (HR 1.06, 95\% CI 1.01-1.12) and experience similar survival to recipients with normal BMI (HR 1.24, 95\% CI 0.90-1.70) [23].

In conclusion, during the early post transplantation period, obese kidney transplant recipients experience an increased frequency of minor surgical complications and an increased incidence of DGF. Although short term outcomes are excellent, in the long term, obese patient and graft survival are slightly inferior compared to normal weight recipients. However, given the significant survival advantage of transplantation compared to HD in this patient group too, every effort should be made to carefully evaluate them before transplantation and not to "exclude" or "bypass" them with the preface of obesity.

\section{Obese potential living donors}

The increasing rates of obesity in the general population result in an increase in BMI among potential living donors. On the other hand, efforts are made worldwide to increase the living donor pool. 
This effort aims to maximize the living donor pool while focusing on ensuring donor quality of life and good health long term.

Long-term data of living kidney donors are sparse. In the hallmark study by Ibrahim in 2009, data from the long-term follow-up of 3698 living kidney donors who had donated between 1963 and 2007 were published. Glomerular filtration rate (GFR) and urinary albumin excretion were measured at a mean of 15 years after donation, while 255 patients underwent iohexol measurement of GFR. Survival, quality of life, general vital status and the prevalence of hypertension and chronic kidney disease were also assessed. The survival of kidney donors was similar to that of the general population cohort matched for age, sex and race or ethnicity group.

End stage renal disease (ESRD) developed in only 11 donors, which comprises a rate of 180 cases per million persons per year, compared to 268 per million per year in the general population. At a mean of 12 years after donation, $85.5 \%$ of the donor group that consisted of 255 donors for whom data were available at this time, had a GFR above $60 \mathrm{ml} / \mathrm{min}, 11.5 \%$ had microalbuminuria, $1.2 \%$ proteinuria and $32 \%$ had developed hypertension. Older age (OR: $1.15, \mathrm{p}<0,001)$ and higher BMI (OR: 1.12, $\mathrm{p}<0.02$ ) were identified as risk factors for reduced GFR and hypertension while time from donation was associated with the development of proteinuria [24].

However, data of two recent studies, which both compared living kidney donors with a preselected group of healthy individuals who would have been eligible for kidney transplantation, show an increased incidence of ESRD in

Kidney donors compared to this "healthy" control group. Muzaale et al. [25] compared a cohort of 96000 kidney donors and a cohort of 20000 similarly screened healthy non-donors. Estimated risk of ESRD at 15 years after donation was 30.8 per 10000 in kidney donors and 3.9 per 10000 in their matched healthy non donor counterparts.

In the second Norwegian study, 190 kidney donors were compared with a control group of 32,621 potentially eligible kidney donors. The risk of ESRD was significantly increased in donors with a relative risk of 11.38 (CI 4.37-29.6) while a significant increase in cardiovascular death (OR 1.40, CI1.03-1.91) was also observed in the kidney donor group [26].

The authors point out that these differences are due to the fact that the general population includes people with co- morbidities and kidney donors must be compared to a "healthier" control group. These new data should be seriously taken into account and implement very strict selection criteria as well as careful information about the potential long-term risks in living donor transplantation.

Moreover, obesity is an independent risk factor for cardiovascular and progressive renal disease. Especially in the kidney, it causes functional and structural alterations in the glomeruli, resulting in a histologic variant of focal segmental glomerulosclerosis described by the term "Obesity- Related-Glomerulopathy".

Functional changes include elevated renal blood flow, hypertension and proteinuria while structural changes comprise glomerulomegaly, podocytopathy mesangial matrix expansion and hypertrophy and progressive development of focal segmental glomerulosclerosis (FSGS).

Regarding the pathophysiological mechanism, Brenner first described a pathologic process of focal and global sclerosis that eventually occurs in the glomeruli with hyperfiltration $[27,28]$. This "hyperfiltration injury" is the result of many conditions. All of them involve reduced number of functioning glomeruli which eventually leads to hyperfiltration and accelerated damage in the remaining nephrons.

Gonzalez et al. [29] showed that the risk of developing proteinuria and worsening renal function after uninephrectomy was higher in patients with a $\mathrm{BMI}>27 \mathrm{Kg} / \mathrm{m}^{2}$.

The pathophysiology of obesity associated renal pathology includes both functional (hemodynamic) and structural changes. Functional abnormalities concern: a) afferent arteriorial vasodilation and efferent arteriorial vasoconstriction, (due to a number of factors like insulin resistance) resulting in increasing glomerular hydrostatic pressure b) activation of the renin -angiotensin system (due to hyperaldosteronism or as a result of salt sensitivity). Meanwhile increased activity of endogenous cardiotonic glycosides exists which is attributed to the excess of salt intake [30].

All these factors further contribute to structural damage. Hyperinsulinemia stimulates the synthesis of growth factors such as Insulin-like growth factor IGF-1 and IGF-2 which promote glomerular hypertrophy. Elevated levels of leptin (due to obesity) cause secretion of Transforming Growth Factor TGF- $\beta 1$ and glomerulosclerosis. Hyperlipidemia leads to oxidative stress, cytokine release and fibrosis though recent studies suggest that a direct toxic effect on podocytes may also exist [31].

Kambham et al. [32] analyzed the impact of obesity related glomerulopathy in 6818 native kidney biopsies between 1996 and 2000. They revealed a progressive increase in the incidence of ORG from $0.2 \%$ between 1986 and 1990 to $2 \%$ between 1996 and 2000 $(\mathrm{p}=0,0001)$. Mean BMI in patients with ORG $(\mathrm{n}=71)$ was $41.7 \mathrm{Kg} /$ $\mathrm{m}^{2}$ (30.9-62.7), while indications for renal biopsy were proteinuria (56\% of patients) or proteinuria and impaired renal function (44\%). Seventy one patients with ORG were compared to fifty patients with idiopathic FSGS (I-FSGS). Patients with ORG were older (42.9 vs. $32,6)$ than patients with I-FSGS, had a lower incidence of nephrotic range proteinuria ( $48 \%$ vs. $66 \%)$ and rarely neprhotic syndrome $(5,6 \%$ vs. 54\%). Histological findings in patients with ORG included : fewer lesions of segmental glomerulosclerosis ( $10 \%$ vs. 39\%), significantly increased incidence of glomerulomegaly $(100 \%$ vs. $10 \%)$ but less extensive podocyte effacement ( $40 \% v s$. $75 \%)$. Finally, progression to ESRD in patients with ORG was remarkably low, only $3.6 \%$ compared to $42 \%$ in the I-FSGS cohort [32].

In summary, the problems the transplant community is facing with obese potential living donors are as follows: a) their population is increasing along with the increase in obesity in the general population b) obesity related glomerulopathy is a well-defined entity and there are sufficient data that this process is accelareted after uninephrectomy c) the two recent studies on renal and overall survival of living donors force special attention particularly in the selection criteria and the living donor counseling. On the other hand, very few data exist about these "marginal" donors and the safety of donation.

There are no definite guidelines as well. In the European Association of Urology (EAU) guidelines for renal transplantation, donor obesity $\left(\mathrm{BMI}>30 \mathrm{Kg} / \mathrm{m}^{2}\right)$ is referred as a relative contraindication [33].

United Kingdom Guidelines for living donor transplantation [34] recommend that:

a) Otherwise healthy overweight patients (BMI $25-30 \mathrm{Kg} / \mathrm{m}^{2}$ ) may safely proceed to kidney donation 
b) Potential kidney donors with moderate obesity (BMI 30$35 \mathrm{Kg} / \mathrm{m}^{2}$ ) should be counseled carefully about the increased risk of peri- operative complications and the long term risk of chronic kidney disease

c) They should be advised to lose weight prior to donation and maintain a BMI less than $30 \mathrm{Kg} / \mathrm{m}^{2}$.

d) Limited data exist on the safety of kidney donation in the very obese $\left(\mathrm{BMI}>35 \mathrm{Kg} / \mathrm{m}^{2}\right)$ and such patients should be discouraged from donating

Data on long term follow up of obese living donors are also limited.

In a single center study, Nogueira et al. [35] evaluated 36 kidney donors with a BMI> $30 \mathrm{Kg} / \mathrm{m}^{2}$ at a median of $6.8 \pm 1.5$ years post donation.

The mean estimated glomerular filtration rate (eGFR) using the MDRD equation at follow-up was $72 \pm 16 \mathrm{ml} / \mathrm{min}$ which corresponds to an absolute decrease in eGFR by

$27 \pm 13 \mathrm{ml} / \mathrm{min}$ from the time of donation. From the 36 donors, $1.7 \%$ had eGFR between $30-60 \mathrm{ml} / \mathrm{min}$, mainly those with a higher prevalence of albuminuria, possibly due to hyperfiltration.

Given the absence of strong guidelines the decision for the eligibility of an overweight living donor should be individualized by also taking into account the often strong will for donation. Potential donors with obesity $\left(\mathrm{BMI}>30 \mathrm{Kgr} / \mathrm{m}^{2}\right)$ should be discouraged from donation, should be advised to lose weight prior to donation - either with nutritional surveillance or with bariatric surgery -to achieve a BMI of $<30 \mathrm{Kg} / \mathrm{m}^{2}$. As for the obese kidney recipients, given the only slightly increased perioperative risk for minor surgical complications, the clear survival advantage over remaining on $\mathrm{HD}$ and the very good long term kidney and patient outcomes, one cannot medically justify their exclusion from transplantation.

\section{References}

1. Bray GA. Obesity in adults: Prevalence, screening and evaluation. Available at: http:// www.uptodate.com/contents/obesity-in-adults-prevalence-screening-evaluation.

2. Prospective Studies Collaboration, Whitlock G, Lewington S, Sherliker P, Clarke $\mathrm{R}$, et al. (2009) Body-mass index and cause-specific mortality in 900000 adults: collaborative analyses of 57 prospective studies. Lancet 373: 1083-1096. [Crossref]

3. Ng M, Fleming T, Robinson M, Thomson M, Graetz N, et al. (2014) Global, regional, and national prevalence of overweight and obesity in children and adults during 19802013: a systematic analysis for the Global Burden of Disease Study 2013. Lancet 384: 766-781.

4. Kasiske BL, Cangro CB, Hariharan S, Hricik DE, Kerman RH, et al. (2001) The evaluation of renal transplantation candidates: clinical practice guidelines. $\mathrm{Am} \mathrm{J}$ Transplant Suppl 2: 3-95. [Crossref]

5. Friedman AN, Miskulin DC, Rosenberg IH, Levey AS (2003) Demographics and trends in overweight and obesity in patients at time of kidney transplantation. Am J Kidney Dis 41: 480-487. [Crossref]

6. Park J, Ahmadi SF, Streja E, Molnar MZ, Flegal KM, et al. (2014) Obesity paradox in end-stage kidney disease patients. Prog Cardiovasc Dis 56: 415-425. [Crossref]

7. Kalantar-Zadeh K, Block G, Humphreys MH, Kopple JD (2003) Reverse epidemiology of cardiovascular risk factors in maintenance dialysis patients. Kidney Int 63: 793-808. [Crossref]

8. Fleischmann E, Teal N, Dudley J, May W, Bower JD, et al. (1999) Influence of excess weight on mortality and hospital stay in 1346 hemodialysis patients. Kidney Int 55: 1560-1567. [Crossref]

9. Leavey SF, McCullough K, Hecking E, Goodkin D, Port FK, et al. (2001) Body mass index and mortality in 'healthier' as compared with 'sicker' haemodialysis patients:results from the Dialysis Outcomes and Practice Patterns Study (DOPPS). Nephrol Dial Transplant 16: 2386-2394. [Crossref]
10. Port FK, Ashby VB, Dhingra RK, Roys EC, Wolfe RA (2002) Dialysis dose and body mass index are strongly associated with survival in hemodialysis patients. $J \mathrm{Am} \mathrm{Soc}$ Nephrol 13: 1061-1066. [Crossref]

11. Kalantar-Zadeh K, Kopple JD, Kilpatrick RD, McAllister CJ, Shinaberger CS, et al (2005) Association of morbid obesity and weight change over time with cardiovascular survival in hemodialysis population. Am J Kidney Dis 46: 489-500. [Crossref]

12. Johansen KL, Young B, Kaysen GA, Chertow GM (2004) Association of body size with outcomes among patients beginning dialysis. Am J Clin Nutr 80: 324-332. [Crossref]

13. Segev DL, Simpkins CE, Thompson RE, Locke JE, Warren DS, et al. (2008) Obesity impacts access to kidney transplantation. J Am Soc Nephrol 19: 349-355. [Crossref]

14. Knoll G, Cockfield S, Blydt-Hansen T, Baran D, Kiberd B, et al. (2005) Canadian Society of Transplantation: consensus guidelines on eligibility for kidney transplantation. CMAJ 173:1181-1184.

15. Chan W, Bosch JA, Jones D, McTernan PG, Phillips AC, et al. (2014) Obesity in kidney transplantation. J Ren Nutr 24: 1-12. [Crossref]

16. Khwaja A1, El-Nahas M (2012) Transplantation in the obese: separating myth from reality. Nephrol Dial Transplant 27: 3732-3735. [Crossref]

17. Furriel F, Parada B, Campos L, Moreira P, Castelo D, et al. (2011) Pretransplantation overweight and obesity: does it really affect kidney transplantation outcomes? Transplant Proc 43: 95-99. [Crossref]

18. Cacciola RA, Pujar K, Ilham MA, Puliatti C, Asderakis A, et al. (2008) Effect of degree of obesity on renal transplant outcome. Transplant Proc 40: 3408-3412. [Crossref]

19. Cannon RM, Jones CM, Hughes MG, Eng M, Marvin MR (2013) The impact of recipient obesity on outcomes after renal transplantation. Ann Surg 257: 978-984. [Crossref]

20. Weissenbacher A1, Jara M, Ulmer H, Biebl M, Bösmüller C, et al. (2012) Recipient and donor body mass index as important risk factors for delayed kidney graft function. Transplantation 93: 524-529. [Crossref]

21. Meier-Kriesche HU, Arndorfer JA, Kaplan B (2002) The impact of body mass index on renal transplant outcomes: a significant independent risk factor for graft failure and patient death. Transplantation 73: 70-74. [Crossref]

22. Glanton CW, Kao TC, Cruess D, Agodoa LY, Abbott KC (2003) Impact of renal transplantation on survival in end-stage renal disease patients with elevated body mass index. Kidney Int 63: 647-653. [Crossref]

23. Hill CJ, Courtney AE, Cardwell CR, Maxwell AP, Lucarelli G, et al. (2015) Recipient obesity and outcomes after kidney transplantation: a systematic review and metaanalysis. Nephrol Dial Transplant 30: 1403-1411. [Crossref]

24. Ibrahim HN, Foley R, Tan L, Rogers T, Bailey RF, et al. (2009) Long-term consequences of kidney donation. N Engl J Med 360: 459-469. [Crossref]

25. Muzaale AD, Massie AB, Wang MC, Montgomery RA, McBride MA, et al. (2014) Risk of end-stage renal disease following live kidney donation. JAMA 311: 579-586. [Crossref]

26. Mjøen G, Hallan S, Hartmann A, Foss A, Midtvedt K, et al. (2014) Long-term risks for kidney donors. Kidney Int 86: 162-167. [Crossref]

27. Brenner BM, Garcia DL, Anderson S (1988) Glomeruli and blood pressure. Less of one, more the other? Am J Hypertens 1: 335-347. [Crossref]

28. Brenner BM, Lawler EV, Mackenzie HS (1996) The hyperfiltration theory: a paradigm shift in nephrology. Kidney Int 49: 1774-1777. [Crossref]

29. González E, Gutiérrez E, Morales E, Hernández E, Andres A, et al. (2005) Factors influencing the progression of renal damage in patients with unilateral renal agenesis and remnant kidney. Kidney Int 68: 263-270. [Crossref]

30. Ritz E, Koleganova N, Piecha G (2011) Is there an obesity-metabolic syndrome related glomerulopathy? Curr Opin Nephrol Hypertens 20: 44-49. [Crossref]

31. Amann K, Benz K (2013) Structural renal changes in obesity and diabetes. Semin Nephrol 33: 23-33. [Crossref]

32. Kambham N, Markowitz GS, Valeri AM, Lin J, D'Agati VD (2001) Obesity-related glomerulopathy: an emerging epidemic. Kidney Int 59: 1498-1509. [Crossref]

33. Kälble T, Lucan M, Nicita G, Sells R, Burgos Revilla FJ, et al. (2005) EAU guidelines on renal transplantation. Eur Urol 47: 156-166. [Crossref] 
34. Joint Working Party of The British Transplantation Society And The Renal Association. United Kingdom Guidelines for living donor kidney transplantation, 3rd edition May 2011. Available at: www.bts.org.uk \& www.renal.org.
35. Nogueira JM, Weir MR, Jacobs S, Breault D, Klassen D, et al. (2010) A study of renal outcomes in obese living kidney donors. Transplantation 90: 993-999. [Crossref]

Copyright: $(02016$ Marinaki S. This is an open-access article distributed under the terms of the Creative Commons Attribution License, which permits unrestricted use, distribution, and reproduction in any medium, provided the original author and source are credited. 